\title{
Aeroelectric structures and turbulence in the atmospheric boundary layer
}

\author{
S. V. Anisimov ${ }^{1,2}$, E. A. Mareev ${ }^{2,3}$, N. M. Shikhova ${ }^{1,2}$, M. V. Shatalina ${ }^{2,3}$, S. V. Galichenko ${ }^{1,2}$, and S. S. Zilitinkevich ${ }^{2,4}$ \\ ${ }^{1}$ Borok Geophysical Observatory of Shmidt's Institute of Physics of the Earth RAS, 152742 Borok, Yaroslavl, Russia \\ ${ }^{2}$ Nizhny Novgorod State University, Radiophysics Faculty, 603024 Nizhny Novgorod, Russia \\ ${ }^{3}$ Geophysical Research Department, Institute of Applied Physics RAS, 603950 Nizhny Novgorod, Russia \\ ${ }^{4}$ Finnish Meteorological Institute, Erik Palmenin aukio 1, PL 503, 00101 Helsinki, Finland
}

Correspondence to: M. V. Shatalina (aries@appl.sci-nnov.ru)

Received: 31 May 2013 - Revised: 9 September 2013 - Accepted: 9 September 2013 - Published: 29 October 2013

\begin{abstract}
Complex electrical measurements with the use of sodar data show that electric field pulsation analysis is useful for electrodynamics/turbulence monitoring under different conditions. In particular, the number of aeroelectric structures (AES) generated per hour is a convenient measure of the turbulence intensity. During convectively unstable periods, as many as 5-10 AES form per hour. Under stable conditions, AES occasionally form as well, indicating the appearance of occasional mixing events reflected in the electric field perturbations. AES magnitudes under stable conditions are relatively small, except in special cases such as high humidity and fog. The analysis of electric field (EF) spectra gives additional useful information on the parameters of the atmospheric boundary layer and its turbulence. A rather sharp change in the spectrum slope takes place in the vicinity of $0.02 \mathrm{~Hz}$ under stable conditions. The characteristic slope of the spectrum and its change are reproduced in a simple model of EF formation.
\end{abstract}

\section{Introduction}

The atmospheric boundary layer is characterized by a variety of physical phenomena, including the processes of generation and transfer of charged particles - ions and charged aerosols and hydrometeors. These electrical processes occur simultaneously with aerodynamical processes and can serve as a useful means for their diagnostics. Furthermore, electrical phenomena and the global electric circuit represent an inherent part of the boundary layer, and deserve special attention (Hoppel et al., 1986; Mareev, 2008).

In the last two decades our understanding of the nature of atmospheric and oceanic turbulence and planetary bound- ary layers (PBLs) has been revised conceptually, taking into account the self-organization processes that strongly affect turbulent transports and make them essentially non-local (Zilitinkevich, 2010; Zilitinkevich et al., 2005, 2006, 2009). It has been recognized that the traditional theory (disregarding these mechanisms), and therefore PBL schemes currently used in environmental models are incapable of realistically reproducing extreme PBL regimes under conditions of strong convection and strong static stability. Interestingly, in parallel with this conceptual revision of the classical picture and independently of it, new ideas on electrical processes in the PBL have been formed. It was found, in particular, that the PBL is marked by the presence of so-called aeroelectric structures (AES) that appeared in the short-period $\left(10^{-3} \div 1 \mathrm{~Hz}\right)$ pulsations of the electric field. AES represent dynamical space-charge inhomogeneities in the boundary layer, indicated in the coherent perturbations of the electric field (Anisimov et al., 1994, 1999, 2002). The analysis allowed quantitative estimations of spatial scales $500-10^{3} \mathrm{~m}$ and temporal scales for these structural elements. Quasiperiodic sequences and high-amplitude solitary AES have been recognized. Three-dimensional structural-temporal patterns were presented, which directly characterize the level of electric energy perturbations connected with AES formation during night-day evolution.

At frequencies of $10^{-2} \div 10^{-1} \mathrm{~Hz}$, the electric field (EF) pulsations were found to be essentially non-local. The most probable values of the index lie in the range from -2.25 to -3.0 , unlike the temperature fluctuation spectra, which obey the Kolmogorov power law with the spectral index close to $-5 / 3$ in the inertial subrange. The relation of spectral characteristics to the formation of AES was found (Anisimov et al., 
2002). Analysis of the mechanisms explains the relationship between electric-field spectra and the neutral-gas turbulence and AES formation, and allows one to recover the parameters of the neutral gas motion (Anisimov et al., 2003; Shatalina et al., 2005, 2007). It was suggested in particular that measuring the short-period $\left(10^{-3} \div 1 \mathrm{~Hz}\right)$ EF pulsations is a convenient instrument for the fog studies and prognosis (Anisimov et al., 2005).

Analysis of spectra and structure functions of EF pulsations (Anisimov et al., 1999, 2003) showed nontrivial properties of space-charge structures, including an effective increase in charge relaxation time and the existence of longterm horizontally extended (up to several kilometers) charge layers. As an example, the analytical solutions were found, describing self-consistent charge layers forming in the lightion environment (Mareeva et al., 1999).

Electric measurements for the PBL study and diagnostics were rarely used. The relationship between electrical parameters and PBL stability was noted by Israelsson and Knudesen (1983). The connection between PBL characteristics and electrode effects in the surface atmospheric layer was analyzed by Hoppel et al. (1986; see also references in this paper) and Israelsson et al. (1994). Structure function application to EF research was introduced by Anisimov et al. (1994). Anisimov et al. (1999, 2002) have analyzed structure functions of electric field pulsations under different meteorological conditions, focusing mostly on unstable fair weather and fog conditions, when the most intense AES are formed. In the present paper the most attention is paid to the stable conditions. Complex measurements of electrical parameters in the atmospheric boundary layer (including EF pulsation analysis) are used to derive information on the characteristics of the boundary layer. The sodar measurements are taken into account, with the emphasis on stable conditions as well.

We should note that the PBL turbulence under the most stable conditions, where it does not obey similarity theory, including the lack of an inertial subrange, has recently attracted much attention (Mahrt et al., 2012; Grachev et al., 2012). Conventional turbulence concepts may not apply to the fluctuating flow. For example, such fluctuations can be characterized by very small correlations, vertical velocity fluctuations and much larger horizontal velocity and temperature variations compared to more conventional turbulence in weakly stable conditions (Mahrt et al., 2012). Little emphasis has been placed earlier on the extensive periods of very weak turbulence between mixing events (Mahrt et al., 2013). Since very weak turbulence accounts for most of the record of very stable conditions, it can contribute significantly to the timeaveraged turbulence and to the heat flux (Mahrt et al., 2012). The degree of "weakness" of this turbulence partly determines the rapid cooling rate, build-up of contaminants and the potential for ground fog. Sun et al. (2012) found that, for very stable regimes, the weak turbulence is relatively insensitive to the magnitude of the stratification.
In the present paper we develop a supplementary approach to these problems connected with electrical measurements.

\section{Instrumentation and method}

We have analyzed summer season 2012 observations performed at the middle-latitude Borok Geophysical Observatory $\left(58^{\circ} 04^{\prime} \mathrm{N}\right.$ and $\left.38^{\circ} 14^{\prime} \mathrm{E}\right)$ under a low level of electromagnetic interference and industrial pollution. The electrostatic fluxmeters developed for long-term work were used as sensors of atmospheric electric field intensity and its variations. The sensor was installed at a height of $1.5 \mathrm{~m}$. The threshold sensitivity of the sensor was about $0.1 \mathrm{Vm}^{-1}$. The dynamic range of the measurements has not been less than $80 \mathrm{~dB}$ (Anisimov et al., 2002, 2007). Values of the electric field were reduced to the surface value by a reduction coefficient that was equal to 0.3 .

Meteorological parameters of a near-surface atmosphere (temperature, windspeed components, humidity, atmospheric pressure, light exposure) were measured simultaneously by means of an ultrasonic meteorological station (Gladkikh and Makienko, 2009) installed at a height of $10 \mathrm{~m}$. Digital registration of all data was carried out with a clock rate of $10 \mathrm{~Hz}$ (Anisimov et al., 2007). The scheme of the experimental setup is shown in Fig. 1.

Doppler acoustic locator (sodar) technique has been used in order to measure vertical profiles of the wind speed components in the PBL and to evaluate the intensity and characteristic scales of the aerodynamic turbulence to be compared with the results of electrical measurements. The technique of sodar measurement is well developed (e.g., Kallistratova et al., 2004; Tamura et al., 2007) and enables the definition of averaged (for 10-60 min) profiles of wind speed and its direction with the accuracy corresponding to meteorological standards. Sodar Volna-3 (Gladkikh et al., 1999) was used during these experiments.

A total of 23 continuous daily series of observations have been analyzed. In this work we use only daily data from fair weather conditions (absence of precipitation, wind speed of no more than $3.5 \mathrm{~ms}^{-1}$, and a cloud amount of no more than 7). Examples of the EF observation records for two days of July 2012 are presented in Fig. 2.

Structure functions of short-period pulsations $\Delta E_{z}$ were calculated using 10-s means data according to the algorithm of stationary increments: $D_{E}(t, \tau)=\left\langle|\Delta E(t+\tau)-\Delta E(t)|^{2}\right\rangle$ (Rytov et al., 1989). For estimation of properties of selfsimilarity: $\left\langle\left|\Delta E_{z}(\tau)\right|^{2}\right\rangle \sim(\tau)_{2}^{\zeta}$ for $\tau$ changes within interval $(1 \div 200) \mathrm{s}, \zeta_{2}$ values were calculated by the least-squares method. Further, $\left\langle\left|\Delta E_{z}(\tau)\right|^{2}\right\rangle$ is calculated as the averaged $D_{E}(t, \tau)$ over $5 \mathrm{~min}$. The number of structures per hour is found using these structure functions. It was considered that for a given 5 min time interval, the structure appeared if the following conditions were carried out:

1. $0.3<\zeta_{2}<1.5$. 




Fig. 1. Experimental set-up scheme.

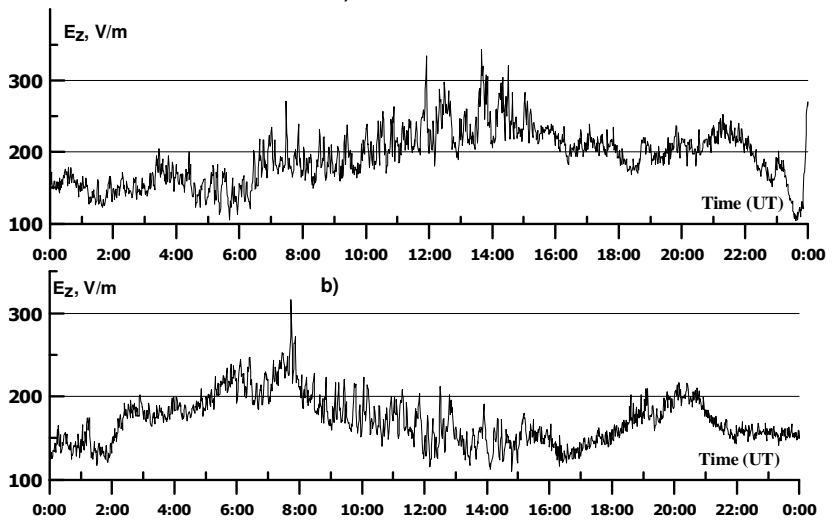

Fig. 2. Electric field observation records of 23 July 2012 (a) and 30 July 2012 (b).

2. $\left\langle\left|\Delta E_{z}(\tau)\right|^{2}\right\rangle$ increases monotonically in the time interval $30 \mathrm{~s}<\tau<120 \mathrm{~s}$.

3. $\left\langle\left|\Delta E_{z}(\tau)\right|^{2}\right\rangle$ is concave at least at 3 points least 3 points of the time interval $80 \mathrm{~s}<\tau<180 \mathrm{~s}$.

4. The gradient Richardson number was calculated each minute using the meteorological parameters registered by the ultrasonic meteo-station, by the expression:

$R i=\frac{g}{\langle\theta\rangle}\left(\frac{\partial \theta}{\partial Z}\right) \frac{1}{\left(\frac{\partial V_{\mathrm{h}}}{\partial Z}\right)^{2}}$,

where $\langle\theta\rangle$ is the mean temperature at the level of $10 \mathrm{~m}$, and $\left(\frac{\partial \theta}{\partial Z}\right)$ and $\left(\frac{\partial V_{\mathrm{h}}}{\partial Z}\right)$ are the temperature and horizon- tal velocity gradients accordingly at the same height. The daily file of the recorded $R i$ was then the subject of low-frequency filtering by the moving average method with the window width of $60 \mathrm{~min}$. Smoothed values of the gradient Richardson number $(R i)$ and the number of structures per the preceding hour $(N)$ are presented in what follows.

\section{Observations and analysis}

EF observation records were the analysis framework. The main focus was the study of AES generation under different stability conditions. A detailed analysis of data from 30 July 2012 is presented (Fig. 2) as a very characteristic example. Sodar echograms display the intensity of the reflected sound signal (the least intense - gray, and the most intense red), depending on the height and time of each of the three antennas, in conventional units (Fig. 3). These records show the transition from quite nocturnal conditions to the convective regime developed about 04:30 UT, which corresponds to 08:30 LT. The results of the structural-temporal analysis are shown in Fig. 4. The number of pronounced AES and their intensity increases during the convective period of a day. The gradient Richardson number behavior during a day and the number of AES per hour are shown in Fig. 5. Two horizontal red lines in Fig. 5 correspond to $R i-0.5$ and 0.5, below and above which stratification of a surface layer can be considered strongly unstable and stable, respectively. The number of AES per hour is obviously related to Ri. During the stable period (from midnight to 03:00 LT, and from 17:00 to next midnight in that particular case), no or few AES are formed, 


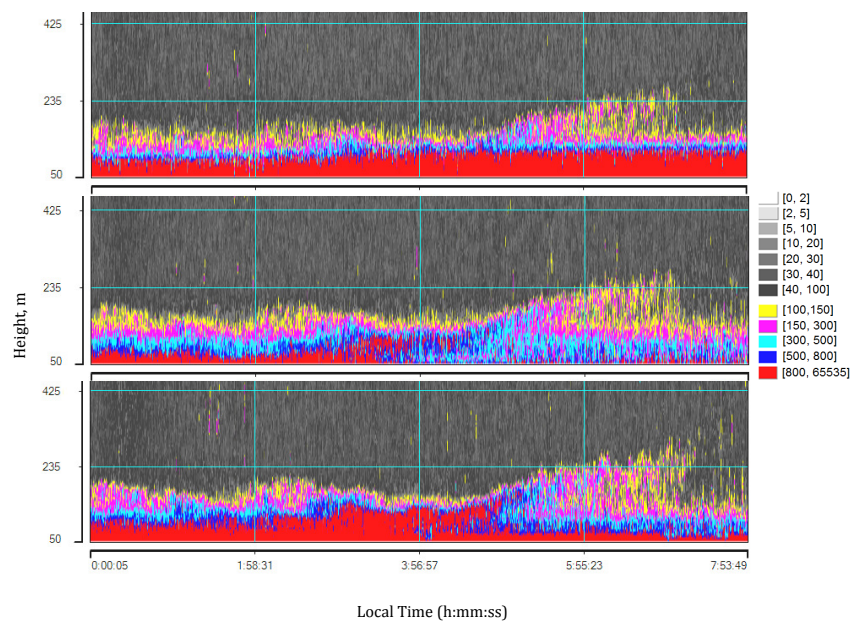

Fig. 3. Sodar echo for 30 July. Three components of the echo signal are shown: vertical (Channel 1, upper panel), North-South (Channel 2, middle panel), and West-East (Channel 3, bottom panel).

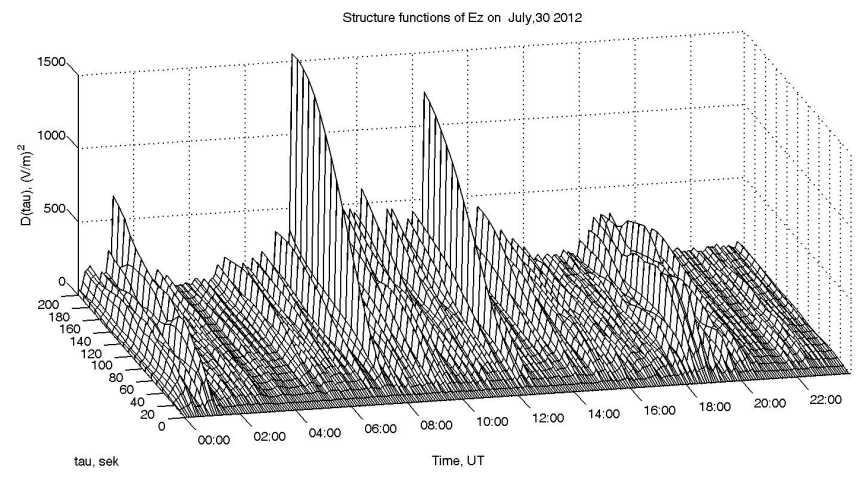

Fig. 4. The results of the structural-temporal analysis. Structure functions are shown for 30 July.

while during convectively unstable periods, as many as 69 AES form per hour. This very characteristic regularity is repeated from day to day during summer. We should note that, under stable conditions, AES form as well from time to time. It shows the appearance of occasional mixing events with weak winds and strong stratification. These events, accounting for a major fraction of the total vertical flux under stable conditions, are reliably reflected in the electric field perturbations.

For a detailed analysis of the turbulence under stable stratification, several time periods were chosen where $\mathrm{Ri}$ was sufficiently high and AES were formed simultaneously. The specific example spectrum is presented (Fig. 6). Calculations were performed for the early morning period 00:3001:30 UT (which corresponds to 04:30-05:30 LT) of 30 July 2012, when the Richardson number was approximately equal to unity. A rather sharp change in the spectrum slope takes place in the vicinity of $0.03 \mathrm{~Hz}$.

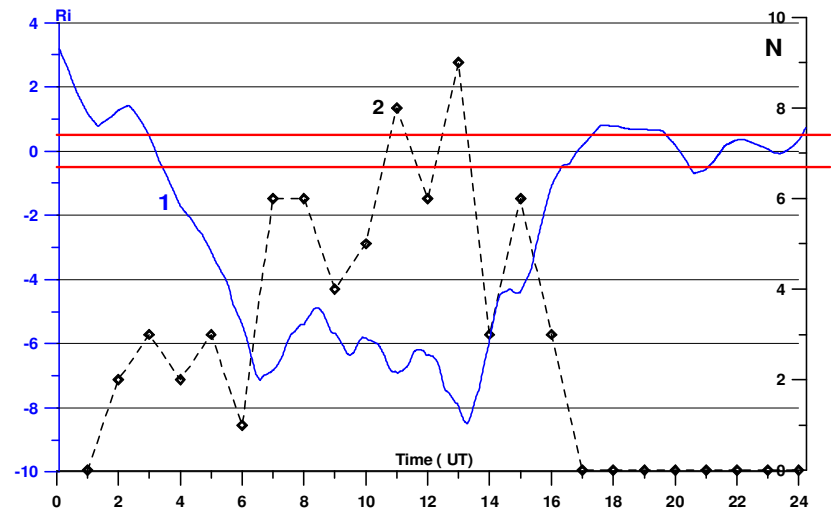

Fig. 5. Dynamics of the number of AES per hour ( $N$, dashed black) and the gradient Richardson number ( $R i$, blue line) during 30 July. The two horizontal red lines correspond to $R i$ values -0.5 and 0.5 .

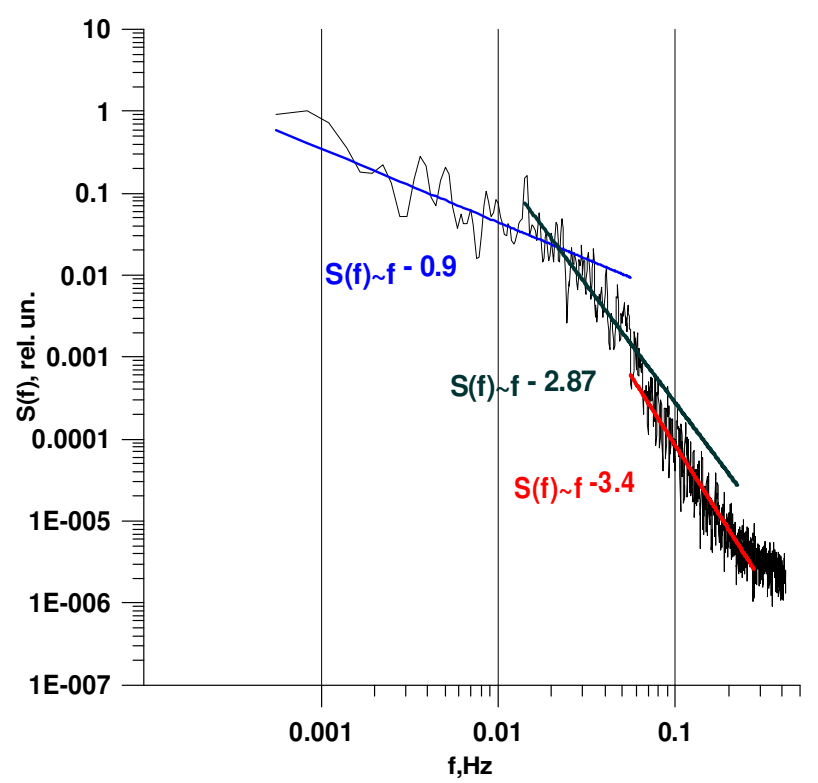

Fig. 6. EF pulsation spectrum for stable conditions (early morning period 00:30-01:30 UT of 30 July).

Two spectra of the same observation day (23 July 2012) are presented in Fig. 7a and b. Spectra were calculated for $2 \mathrm{~h}$ periods, each with essentially different stability conditions: 21:00-23:00 UT (stable conditions, $R i \approx 1$ ), which corresponds to the nocturnal period 01:00-03:00 LT of 24 July 2012, and 06:00-08:00 UT (unstable conditions, $R i \approx-$ 5.5). The spectra approximations in the range of $0.01-0.3 \mathrm{~Hz}$ are shown. It is obvious that, under stable conditions, a rather sharp change in the spectrum slope occurs as well (similar to the spectrum in Fig. 6) near the frequency $0.02 \mathrm{~Hz}$ in this case. It can be compared directly with the smoother behavior of the spectrum as a whole including low frequencies and high frequencies under unstable conditions. A more detailed explanation of this fracture and its interrelation with 

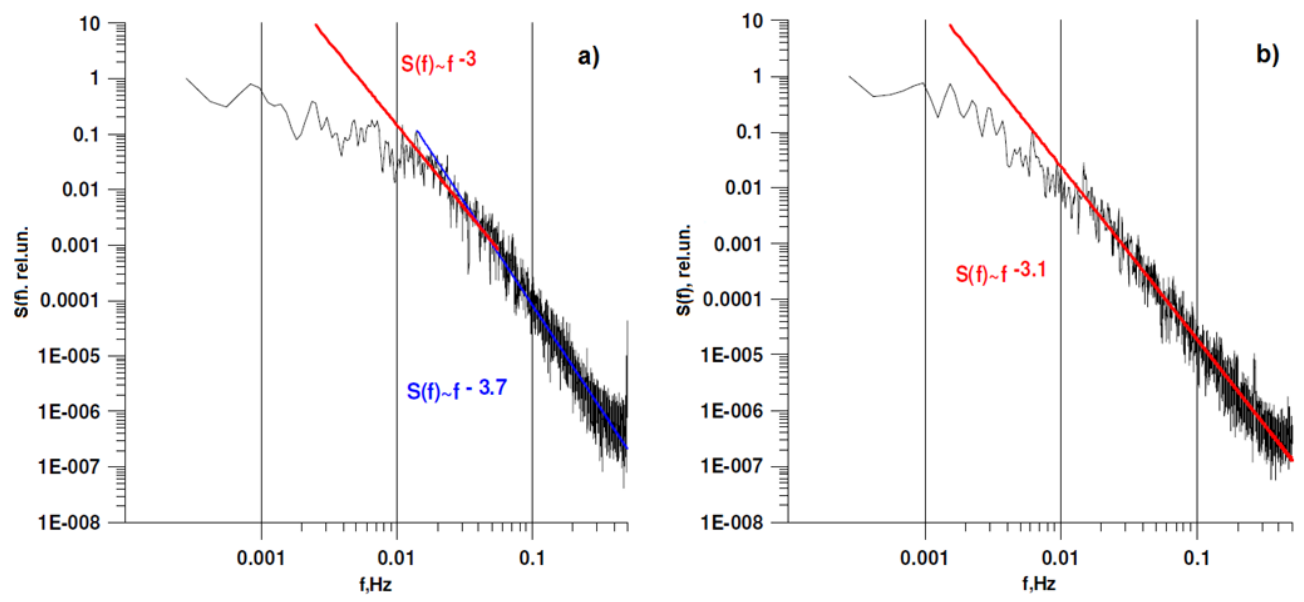

Fig. 7. Two spectra (a, b) of the same observation day (23 July) calculated for two-hour periods, each with different stability conditions: (a) 21:00-23:00 UT (stable conditions, $R i \approx 1$ ), and (b) 06:00-08:00 UT (unstable conditions, $R i \approx-5.5$ ).

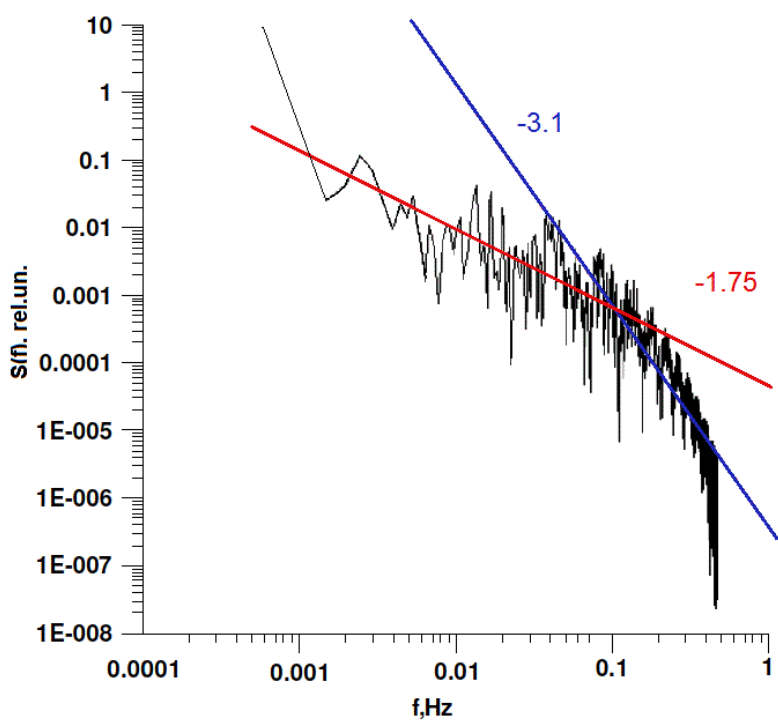

Fig. 8. An example of the EF spectrum, generated by the flow of electric charges (probe sources) distributed over the layer of $100 \mathrm{~m}$ in height.

the boundary layer parameters requires a more explicit theoretical consideration (respective approaches are discussed by Anisimov et al., 2001) and will be presented elsewhere. We confined the present analysis to an example of the EF spectrum (Fig. 8), generated by the flow of electric charges (probe sources) and calculated on the basis of the approach suggested Anisimov et al. (2003) and Shatalina et al. (2005). Calculations using the Coulomb law have been performed for a number $\left(10^{3}\right)$ of charged probe sources occupying the layer of $100 \mathrm{~m}$ in height. The charges of the sources and the initial distribution over the horizontal coordinate were randomly taken. The vertical velocity of the sources was equal to zero for simplicity; a horizontal wind speed was taken of
$1 \mathrm{~ms}^{-1}$. It is seen in Fig. 8 that the characteristic slope of the spectrum and its fracture are reproduced even in a simple model. The model complication and allowance for the PBL height, speed profile and distribution of charges over the probe sources will be a topic of further studies.

\section{Conclusions}

We can conclude from the analysis results of the complex electrical measurements with the use of sodar data that EF pulsation analysis serves as a powerful means of electrodynamics/turbulence monitoring under different conditions. It is especially important that the number of AES generated per time unit is a convenient measure of turbulence intensity. AES magnitudes under stable conditions are relatively small, except in special cases such as high humidity and fog. During a stable period, no or few AES are formed, while during a convectively unstable period, 5-10 AES are formed per hour. This regularity is very characteristic and is repeated from day to day during the summer. It should be noted however that, under stable conditions, from time to time AES form as well, which indicates the appearance of occasional mixing events with weak winds and strong stratification. These events, accounting for a major fraction of the total vertical flux under stable conditions, are reliably reflected in the electric field perturbations.

The analysis of EF spectra gives additional useful information on the parameters of the atmospheric boundary layer and its turbulence. A rather sharp change in the spectrum slope takes place in the vicinity of $0.02 \mathrm{~Hz}$ under stable conditions. The characteristic slope of the spectrum and its change are reproduced in a simple model of EF pulsation formation. The model complication and allowance for the PBL height, speed profile and distribution of charges over the probe sources will be a topic of further theoretical studies, together with their 
coupling with experimental data for the PBL characterization and the development of new methods of its operative diagnostics.

Acknowledgements. This work has been supported by the Russian Federation Government Grant No. 11.G34.31.0048 "Air-sea/land interaction: physics and observation of planetary boundary layers and quality of environment" and the ERC Grant No. 227915 "Atmospheric planetary boundary layers - physics, modelling and role in Earth system".

Edited by: I. Esau

Reviewed by: two anonymous referees

\section{References}

Anisimov, S. V., Bakastov, S. S., and Mareev, E. A.: Spatiotemporal structures of electric field and space charge in the surface atmospheric layer, J. Geophys. Res., 99, 10603-10610, 1994.

Anisimov, S. V., Mareev, E. A., and Bakastov, S. S.: On the generation and evolution of aeroelectric structures in the surface layer, J. Geophys. Res., 104, 14359-14368, 1999.

Anisimov, S. V., Mareev, E. A., Shikhova, N. M., and Dmitriev, E. M.: Mechanisms of formation of pulsation spectra of the electric field in the surface atmospheric layer, Radiophys. Quantum El., 44, 520-532, 2001.

Anisimov, S. V., Mareev, E. A., Shikhova, N. M., and Dmitriev, E. M.: Universal spectra of electric field pulsations in the atmosphere, Geophys. Res. Lett., 29, 2217-2220, 2002.

Anisimov, S. V., Shikhova, N. M., Mareev, E. A., and Shatalina, M. V.: Structures and spectra of turbulent pulsations of aeroelectric field, Izv. RAN. - Atmospheric and Ocean Physics, 39, N6, 766781, 2003.

Anisimov, S. V., Mareev, E. A., Shikhova, N. M., Sorokin, A. E., and Dmitriev, E. M.: On the electro-dynamical characteristics of the fog, Atmos. Res., 76, 16-28, 2005.

Anisimov, S. V., Chulliat, A., and Dmitriev, E. M.: Informationmeasuring complex and database of mid-latitude Borok Geophysical Observatory, Russian Journal of Earth Sciences, 10, es3007, doi:10.2205/2007es000227, 2007.

Gladkikh, V. A. and Makienko, A. E.: Digital Ultrasonic Weather Station, Pribory, 7, 21-25, 2009.

Gladkikh, V. A., Makienko, A. E., and Fedorov, V. A.: Acoustic Doppler radar "Volna-3", Atmospheric and Oceanic Optics, 12, 437-444, 1999.

Grachev, A., Andreas, E., Fairall, C., Guest, P., and Persson, P.: Outlier problem in evaluating similarity functions in the stable atmospheric boundary layer, Bound.-Lay. Meteorol., 144, 137-155, 2012.

Hoppel, W. A., Anderson, R. V., and Willett, J. C.: Atmospheric electricity in the planetary boundary layer, in: The Earth's Electrical Environment, edited by: Krider, E. P. and Roble, R. G., National Academy Press, Washington, D.C., 149-165, 1986.

Israelsson, S. and Knudsen, E.: Some local effects of atmospheric electrical parameters, in: Proceedings in atmospheric electricity, edited by: Ruhnke, L. H. and Latham, J., A. Deepak Publishing, Hampton, Virginia, 135-138, 1983.
Israelsson, S., Knudsen, E., and Anisimov, S. V.: Vertical profiles of electrical conductivity in the lowermost part of the turbulent boundary layer over flat ground, J. Atmos. Terr. Phys., 56, 15451550, 1994.

Kallistratova, M. A. and Coulter, R. L.: Application of sodars in the study and monitoring of the environment, Meteorol. Atmos. Phys., 85, 21-37, 2004.

Mahrt, L., Richardson, S., Seaman, N., and Stauffer, D.: Turbulence in the nocturnal boundary layer with light and variable winds, Q. J. Roy. Meteor. Soc., 138, 1430-1439, 2012.

Mahrt, L., Thomas, C., Richardson, S., Seaman, N., Stauffer, D., and Zeeman, M.: Non-stationary generation of weak turbulence for very stable and weak-wind conditions, Bound.-Lay. Meteorol., 147, 179-199, 2013.

Mareev, E. A.: Formation of Charge Layers in the Planetary Atmospheres, Space Sci. Rev., 137, N1-4, doi:10.1007/s11214-0089306-2, 2008.

Mareeva, O. V., Mareev, E. A., Israelsson, S., and Anisimov, S. V.: Synergetic models of space charge structures in the atmosphere, in: Proc. 11th Int. Conf. on Atmospheric Electricity, Gunterswille, USA, 614-617, 1999.

Rytov, S. M., Kravtsov, Yu. A., and Tatarskii, V. I., Principles of Statistical Radiophysics, Vol. 3, Random Fields, Springer, Berlin, Heidelberg, 1989.

Shatalina, M. V., Mareev, E. A, Anisimov, S. V., and Shikhova, N. M.: Modeling of the Electric-Field Dynamics in the Atmosphere Using the Test-Structure Method, Radiophys. Quantum El., 48, 575-586, doi:10.1007/s11141-005-0102-x, 2005.

Shatalina, M. V., Mareev, E. A., Anisimov, S. V., and Shikhova, N. M.: Recovery of space charge distribution by the method of test structures, in: Proc. Int. Conf. on Atm. Electr. (ICAE 07), Beijing, August 2007.

Sun, J., Mahrt, L., Banta, R., and Pichugina, Y.: Turbulence regimes and turbulence intermittency in the stable boundary layer during CASES-99, J. Atmos. Sci., 69, 338-351, 2012.

Tamura, Y., Iwatani, Y., Hibi, K., Suda, K., Nakamura, O., Maruyama, T., and Ishibashi, R.: Profiles of mean wind speeds and vertical turbulence intensities measured at seashore and two inland sites using Doppler sodars, J. Wind Eng. Ind. Aerod., 95, 411-427, 2007.

Zilitinkevich, S. S.: Geophysical turbulence and planetary boundary layers, Geophys. J., 6, 168-174, 2010.

Zilitinkevich, S. S. and Esau, I. N.: Resistance and heat transfer laws for stable and neutral planetary boundary layers: Old theory advanced and re-evaluated, Q. J. Roy. Meteor. Soc., 131, 18631892, 2005.

Zilitinkevich, S. S., Hunt, J. C. R., Grachev, A. A., Esau, I. N., Lalas, D. P., Akylas, E., Tombrou, M., Fairall, C. W., Fernando, H. J. S., Baklanov, A., and Joffre, S. M.: The influence of large convective eddies on the surface layer turbulence, Q. J. Roy. Meteor. Soc., 132, 1423-1456, 2006.

Zilitinkevich, S. S., Elperin, T., Kleeorin, N., L'vov, V., and Rogachevskii, I.: Energy- and flux-budget (EFB) turbulence closure model for stably stratified flows. Part II: The role of internal gravity waves, Bound.-Lay. Meteorol., 133, 139-164, 2009. 